\title{
MIGRAÇÃO INTERNA \\ EM TEMPOS DE CRISE NO BRASIL \\ INTERNAL MIGRATION IN TIMES OF CRISIS IN BRAZIL
}

\author{
EDnelson Mariano Dota* \\ Silvana Nunes de QueIroz** \\ * Universidade Federal do Espírito Santo, Vitória, ES, Brasil. \\ **Universidade Regional do Cariri, Crato, CE, Brasil e Universidade Federal do Rio Grande do Norte, Natal, RN, Brasil.
}

\begin{abstract}
R E S U M O : Em um cenário marcado pela crise econômica que atinge o Brasil desde 2011 com aumento do desemprego e informalidade, após um decênio em que, apesar do baixo crescimento econômico, observou-se geração de postos de trabalho formais e relativa desconcentração da atividade econômica entre as regióes do país - este estudo tem como objetivo analisar a relação entre fluxos migratórios e conjuntura econômica, precisamente os impactos da recente crise econômica na migraçáo de longa (inter-regional), média (intrarregional) e curta distância (intraestadual). Os resultados reforçam a importância do contexto econômico e demográfico para a dinâmica migratória, ao verificar queda no volume dos fluxos de longa e média distância e a intensificação dos fluxos de curta distância, além do retorno das trocas migratórias entre regióes a padrôes de décadas anteriores, bem como mostra novas áreas de atração populacional.
\end{abstract}

P A L A V R A S - C H A V E : Crise; Migraçôes; Inter-regional; Intrarregional, Intraestadual.

A BS TR ACT: In a scenario marked by the economic crisis that has hit Brazil since 2011 with rising unemployment and informality, after a decade when, despite the limited economic growth, there was observable generation of formal jobs and a relative de-concentration of regional economic activity between the country's regions -, this study aims to analyze the relationship between migratory flows and economic conjuncture; more precisely the impacts of the recent economic crisis on long (inter-regional), medium (intraregional) and short distance (intrastate) migration. To achieve this goal, the microdata of the National Research by Residence (PNAD) between 2005 and 2015 were the main sources of information. The results reinforce the importance of economic and demographic context for migratory dynamics. We verify a decrease in the volume of long and medium distance flow and the intensification of short distance flow, in addition to the return of migratory exchange rates between regions to patterns of previous decades, as well as the appearance of new areas attracting population.

KE Y W O R D : Crisis; Migration; Inter-regional; Intraregional, Intrastate.

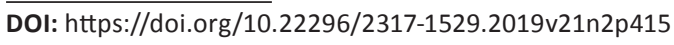




\section{INTRODUÇÃO}

Os períodos de crise vivenciados nas economias capitalistas são recorrentes e os seus impactos são dramáticos, pois dilaceram as condiçóes de vida da população pelo aumento do desemprego, pelo subemprego, pela concentração de renda, pobreza, fome, entre outros.

Nesses momentos críticos e de maneira individual, lança-se mão de estratégias de amenização dos problemas, como apoio em redes sociais e familiares ou até deslocamentos espaciais em busca de melhores oportunidades em outras localidades. São as migraçôes em tempos de crise que este artigo analisa, mais especificamente motivado pelo seguinte questionamento: estaria a crise atual provocando impactos na dinâmica migratória brasileira?

Cabe destacar que esta crise sucedeu após uma década de crescimento econômico modesto, ao longo dos anos 2000, mas com geraçáo de empregos formais, distribuição de renda, política de valorização do salário mínimo e um conjunto de programas sociais e/ou de transferência de renda que impactou positivamente a evolução da estrutura social brasileira (QUADROS, 2011, DIEESE, 2012).

Os períodos de crise tendem a modificar drasticamente a dinâmica demográfica. Análises da década de 1980 indicaram que a crise representou um freio à migração de longa distância pela falta de perspectiva de emprego em regiôes mais desenvolvidas do país, notadamente no sudeste brasileiro (MARTINE; NEIVA; MACEDO, 1984; PACHECO; PATARRA, 1997).

Em relaçáa ao contexto atual, cabe destacar que, do ponto de vista econômico, político, social, demográfico e territorial, o Brasil se encontra em outro patamar quando comparado às décadas de 1980 e 1990. Nesse sentido, seria de se esperar que os impactos da crise econômica sobre a migraçáo inter-regional e intrarregional tendessem a ser diferentes do observado há 30 anos (década de 1980). De todo modo, a resposta para essa questão está intimamente relacionada à importância da dimensão econômica como condicionante para os fluxos migratórios e as persistentes desigualdades regionais (SINGER,1976).

Partimos da hipótese de que, na aparência, os resultados desta recente crise vivenciada pelo Brasil, precisamente durante o segundo decênio do século XXI, têm efeitos sobre a forte redução dos fluxos migratórios de longa (inter-regional) e média distância (intrarregional). Na essência, por outro lado, há o fortalecimento dos movimentos de curta distância (intraestaduais), que resultam das transformaçôes vivenciadas pelo país ao longo destes 30 anos.

Para analisar os impactos da crise atual na migração, o recorte analítico são as cinco grandes regiôes brasileiras, a partir da análise do saldo migratório e do Índice de Eficácia Migratória (IEM), por meio dos microdados da Pesquisa Nacional por Amostra de Domicílios (PNAD) de 2005 e 2015. Os dez anos entre 2005 e 2015 serão analisados comparativamente a partir da migração inter-regional, intra-regional e intraestadual, durante o primeiro interregno (2000/2005), período caracterizado como estável e com crescimento econômico modesto, e o segundo interregno (2010/2015), marcado por baixo crescimento econômico e instabilidades de ordem política e social.

Portanto, espera-se como resultado contribuir para um melhor entendimento dos impactos da crise econômica na migração de longa (inter-regional), média (intrar- 
regional) e curta distância (intraestadual), e da relação atual entre esses fluxos e a conjuntura econômica.

\section{QUESTÕES ECONÔMICAS E FLUXOS MIGRATÓRIOS}

A relação entre a migração e as questóes econômicas é grande e extensivamente explorada pelos estudiosos do tema. Seja nas teorias neoclássicas, em que a migração é analisada como resultado de escolhas individuais (LEWIS, 1969) ou nas histórico-estruturais, em que os condicionantes estruturais e conjunturais predominam na explicação dos movimentos (GAUDEMAR, 1972), a relação aparece como fator de primeira ordem para a interpretação dos volumes e padrôes dos fluxos observados.

Como fenômeno social, os condicionantes congregam múltiplas facetas inviabilizando a elaboração de uma teoria conclusiva (ZELINSKY, 1980). Essa complexidade emana da natureza multidisciplinar do fenômeno migratório (CASTIGLIONI, 2009) e envereda por questóes conceituais, metodológicas e de disponibilidade de dados para comprovação empírica (CUNHA, 2011).

Ao longo da segunda metade do século XX, os fatores de expulsão e estagnação do campo (SINGER, 1976) levaram milhóes de trabalhadores para as cidades, e parte considerável dos fluxos se destinou ao estado de São Paulo, atraída pelo destacado desenvolvimento industrial e da agricultura (PACHECO; PATARRA, 1997), e possibilidade de inserção no mercado de trabalho.

A capacidade de receber e oferecer oportunidades laborais que vigorou até o final da década de 1970 sustentou a existência de volumosos fluxos para São Paulo originados principalmente do Nordeste e norte de Minas Gerais. Nos anos 1980, entretanto, alteraçóes consideráveis foram observadas: segundo Pacheco e Patarra (1997), a crise econômica vivenciada pelo país resultou em fluxos menos volumosos para as metrópoles concomitantemente com o aumento da migração de retorno e da migração intrarregional e intraestadual (NUNES; SILVA; QUEIROZ, 2017).

Junto à recessão econômica, outras mudanças em curso foram impactadas e serviram como alternativa (MARTINE; NEIVA; MACEDO, 1984). Conforme destacam Cunha e Baeninger (2007), a interiorização do desenvolvimento a partir da desconcentração industrial gerou novas centralidades e "espaços de migração" que, no momento de crise, serviram como alternativa à migração de longa distância.

A complexidade da migração se evidencia na constatação de que a década de 1980 não representou, como esperado pelos especialistas, um ponto de inflexão, tendo em vista que, na década seguinte (anos 1990), os volumes de migração voltaram a crescer (CUNHA; BAENINGER, 2007). Especificamente, nesse caso, a emigração a partir do Nordeste, que se esperava menor por conta dos investimentos recebidos e pelas transformaçôes observadas na região.

Por sua vez, nos anos 2000, momento em que vários dos processos em ebulição nas décadas anteriores já estavam arrefecidos, como a desconcentração industrial e a urbanização, a migração apresentou novas tendências: segundo Baeninger (2008), os movimentos de longa distância apresentaram novos trajetos e significados, ao mesmo tempo em que as dinâmicas regionais imprimiram especificidades aos movimentos urbanos-urbanos, predominantes desde os anos 1980. 
A novidade nas interpretaçóes sugere uma relativizaçáo da importância do fator econômico como condicionante dos fluxos de longa distância, sobretudo naqueles do Nordeste para São Paulo. Segundo Brito (2015), tendo em vista que não há mais inserção produtiva como antes, não haveria sustentação para a atratividade por parte de São Paulo. O autor entende que a manutenção de volumosos fluxos seria resultado de uma cultura da migração, e que as redes migratórias e sociais formadas ao longo de décadas de idas e vindas, juntamente com as desigualdades econômicas e sociais, espacialmente materializadas, é que sustentariam a continuidade dos movimentos.

[...] como as trajetórias são caminhos estruturais e têm, portanto, uma dimensão social e cultural, um fator inercial pode mantê-las, mesmo que as condiçôes objetivas da economia e da sociedade já não precisem tanto da força de trabalho que transita por elas. (BRITO, 2015, p.13)

A relativização do fator econômico levaria a supor que os impactos de uma crise econômica seriam sentidos com menor intensidade do que em décadas anteriores. Para a década de 1980, Martine, Neiva e Macedo (1984) consideravam duas possibilidades contraditórias como resultado: (1) o aumento da mobilidade e dos fluxos como resposta à busca pela sobrevivência inviabilizada pela crise ou (2) a redução dos volumes pela falta de oportunidades generalizadas, que anulariam o motivo de se deslocar.

Se, na década de 1980, a crise reduziu os fluxos inter-regionais (longa distância) e aumentou o retorno e os fluxos de média e curta distância (MARTINE; NEIVA; MACEDO, 1984; CUNHA; BAENINGER, 2007; BRITO, 2015), espera-se, no contexto atual, que os resultados da crise na dinâmica migratória incidam no arrefecimento do volume dos fluxos de longa distância e menos nas migraçôes de curta (intraestadual) e média distância (intrarregional), que devem ter se intensificado em termos relativos. Essa perspectiva, mesmo em um contexto diferente do de 30 anos atrás, se assenta na continuidade da relevância do contexto econômico como condicionante da migração, ao mesmo tempo em que as desigualdades regionais, apesar de amenizadas, persistem.

\section{O CONTEXTO ECONÔMICO PÓS-2000}

Analisar a relação entre migração e crise econômica não é uma tarefa trivial, tendo em vista os múltiplos fatores que contribuem para a geração e o direcionamento dos fluxos. Martine, Neiva e Macedo (1984), refletindo sobre essa dificuldade, ressaltam que, mesmo a mobilidade tendo outras razóes e motivaçôes, ela dependeria de um emprego e um nível de renda condizente. Partindo dessa premissa, nesta seção, se analisará a evolução dos empregos e da População em Idade Ativa (PIA), de modo a compreender como a crise pode ter impactado a existência e o surgimento de oportunidades laborais.

$\mathrm{Na}$ década de 1990, mais especificamente entre os anos de 1990 e 2003, a dinâmica do mercado de trabalho brasileiro não apresentou bons resultados, já que o PIB (Produto Interno Bruto) do período foi menor do que o incremento de pessoas na PIA (DEDECCA; ROSANDISKI, 2006). Os anos subsequentes do século XXI foram 
marcados por melhores resultados, dado que, entre 2003 e 2013, observou-se crescimento econômico com geração de empregos formais (DIEESE, 2012) e melhoria dos salários, reestruturando o mercado de trabalho nacional (CAMPOS, 2016).

Entre 2005 e 2015, 19,1 milhóes de pessoas ingressaram na População em Idade Ativa (PIA - 15 a 64 anos) no Brasil, volume que é fruto das mudanças na estrutura etária brasileira. O país passa pelo período denominado de "janela de oportunidades", em que a proporção de pessoas em idade ativa torna-se alta em comparação à proporção de crianças e idosos, considerados potencialmente dependentes. Se, do ponto de vista econômico, esse equilíbrio é favorável para a geração de riquezas, ao mesmo tempo é desafiador, pois representa um aumento da populaçáo potencialmente ativa e na demanda por empregos. ${ }^{1}$

No mesmo período, o volume de pessoas ocupadas aumentou em 9,1 milhóes, indicando que a abertura de novas oportunidades de trabalho náo foi suficiente para cobrir o crescimento da demanda em potencial do país (19,1 milhôes). Apesar da evolução nos indicadores de emprego e renda (Gráfico 1), as regiôes Norte e Nordeste permaneceram com resultados inferiores em comparação às outras regiões do Brasil.

Gráfico 1 - Crescimento percentual da População Ocupada (PO) e da População em Idade Ativa (PIA) - Grandes regiōes e Brasil - 2005/2015

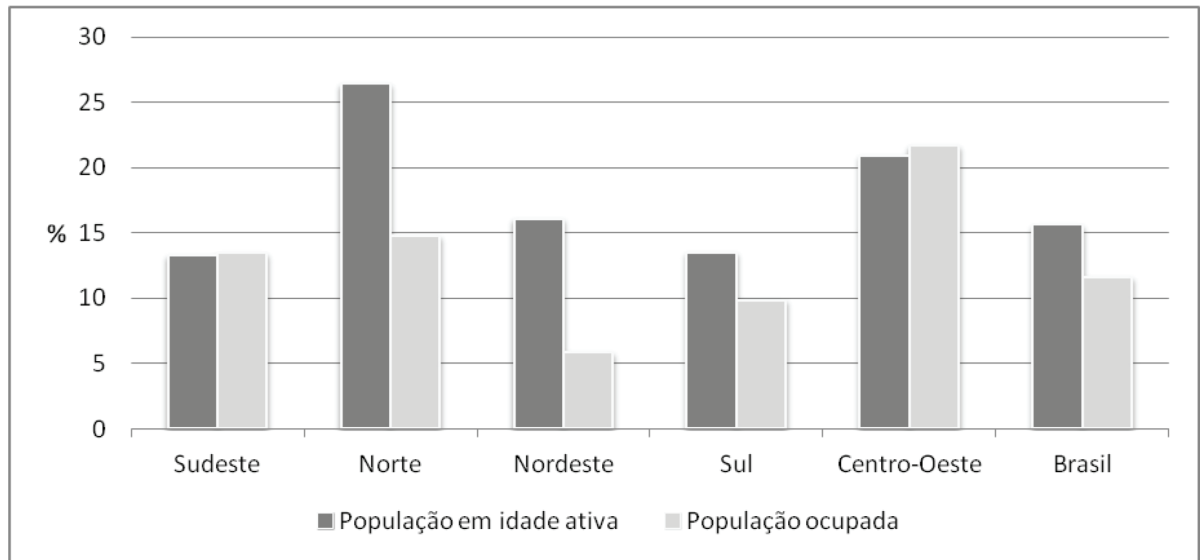

Fonte: Fundação IBGE. PNAD de 2005 e 2015. Elaborado pelos autores.

Essas diferenças regionais são observadas na comparação entre o crescimento percentual da PIA e da populaçấo ocupada entre 2005 e 2015: os dados indicam que enquanto no Centro-Oeste a população ocupada cresceu ligeiramente mais do que a PIA, no Sudeste houve equilíbrio, e no Norte, Sul e, principalmente, no Nordeste (onde a diferença foi maior, 5,2 milhóes de pessoas passaram a fazer parte da PIA enquanto o número de pessoas ocupadas aumentou em 1,1 milháo), o mercado de trabalho não acompanhou a entrada de pessoas nas idades potencialmente produtivas, aumentando a pressão por novas vagas nessas regióes.

Em termos de taxa de participação (Gráfico 2), ou seja, a proporção da PIA ocupada, as diferenças regionais são marcantes: no Brasil, aproximadamente 64\% da PIA esteve ocupada nos três períodos considerados (2005-2008, 2009-2011 e 2012-2015), sendo que a região Sul apresentou os valores mais altos $(70,7 \%, 69,0 \%$ e $67,5 \%$, respectivamente) e o Nordeste os menores $(64,7 \%, 61,2 \%$ e $60,2 \%$, respecti-
1 Sugerimos, para um melhor aprofundamento do debate sobre transição demográfica, janela de oportunidades e estrutura etária da população brasileira, ver Brito et al. (2008). 
vamente). É preciso frisar que em todas regiōes houve recuo na taxa de participação.

Gráfico 2 - Taxa média de participação da População em Idade Ativa (\%) - Grandes regióes e Brasil - 2005-2015

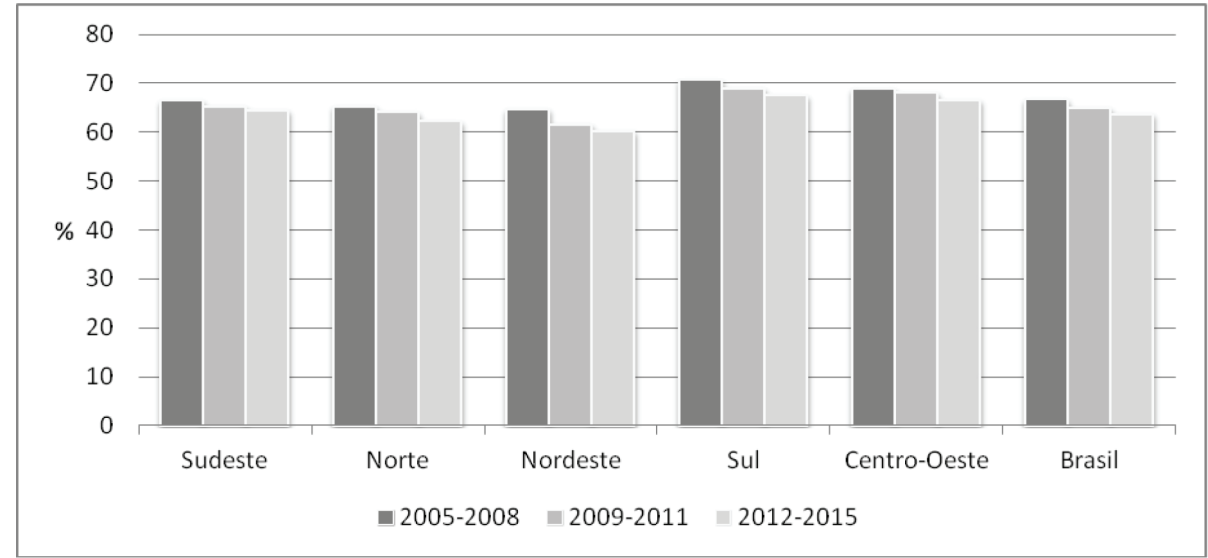

Fonte: Fundação IBGE. PNAD de 2005 a 2015. Elaborado pelos autores.

Em certa medida, é possível que as variações verificadas estejam relacionadas com a conjuntura econômica dos períodos: entre 2005 e 2007, o Brasil passava por um período de crescimento consistente (Gráfico 3), mas, em 2009, parece que sofreu os impactos da crise imobiliária americana de 2008, que culminou na redução verificada, conforme ratificam Paula e Pires (2017, p.126): “(...) em 2009 houve uma breve recessão devido ao contágio da crise mundial”. Em 2010, contudo, retoma o crescimento da economia e, no período que se segue (2011 a 2015), houve significativo decréscimo no PIB brasileiro, com exceção de 2013, dinâmica essa também associada à instabilidade política que o país vive na atualidade.

Gráfico 3 - Produto Interno Bruto (PIB) (\%) - Taxa de Crescimento Real Anual Brasil - 2005-2015

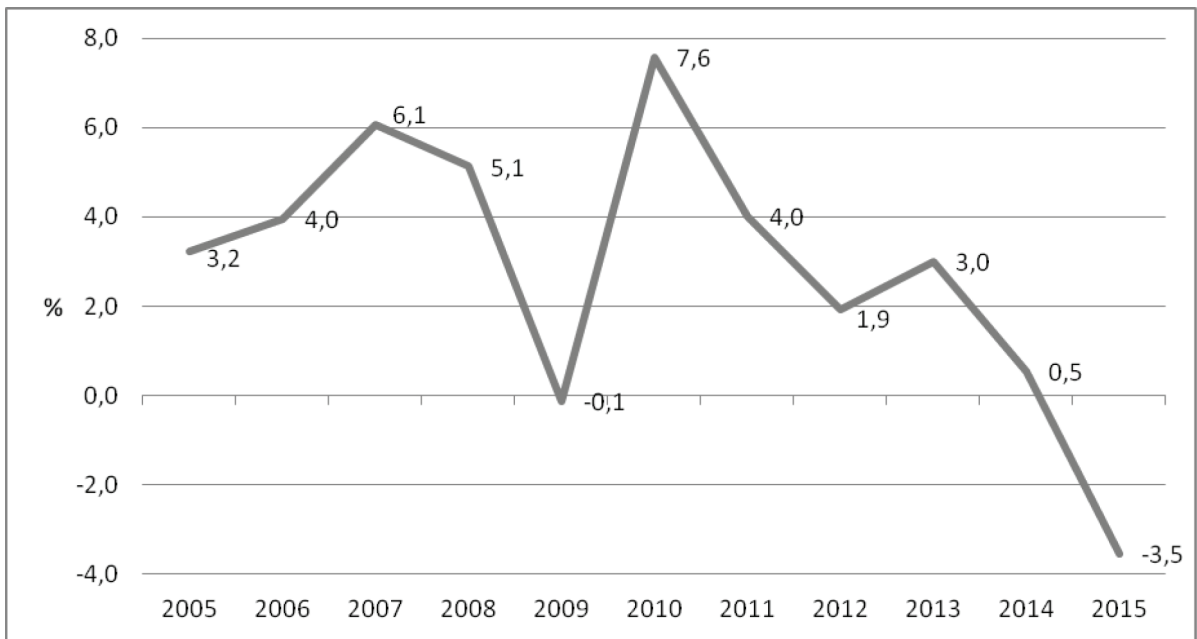

Fonte: IPEA-Data. Organizado pelos autores.

No tocante à dinâmica do mercado de trabalho, houve momentos distintos entre o primeiro (2005-2010) e o segundo período (2011-2015): no primeiro, com 
o crescimento econômico (exceção do ano de 2009 - Gráfico 3), houve a geração de empregos formais (Gráfico 4), com o saldo de vagas anual ultrapassando a cifra de 1 milhão de postos de trabalho, e atingiu-se um contingente de mais de 2 milhóes de vagas criadas somente em 2010. Entretanto, nesse primeiro momento, a exceçáo foi o ano de 2009, cujo baixo crescimento do PIB refletiu-se no mercado de trabalho brasileiro, que criou menos de 1 milhão de empregos (995.111).

Contudo, no segundo período (2011-2015), a desaceleração provocada pela crise econômica em anos recentes representou redução considerável no saldo de vagas criadas no Brasil, que passou de positivo durante toda a série para a "queima" de vagas ou saldo negativo em 2015 (-1,6 milhão). É possível observar no Gráfico 4 que, desde 2011, o país segue uma tendência decrescente na geraçáo de postos de trabalho, até atingir o seu pior momento em 2015.

Gráfico 4 - Saldo de vagas formais - Brasil - 2005-2015

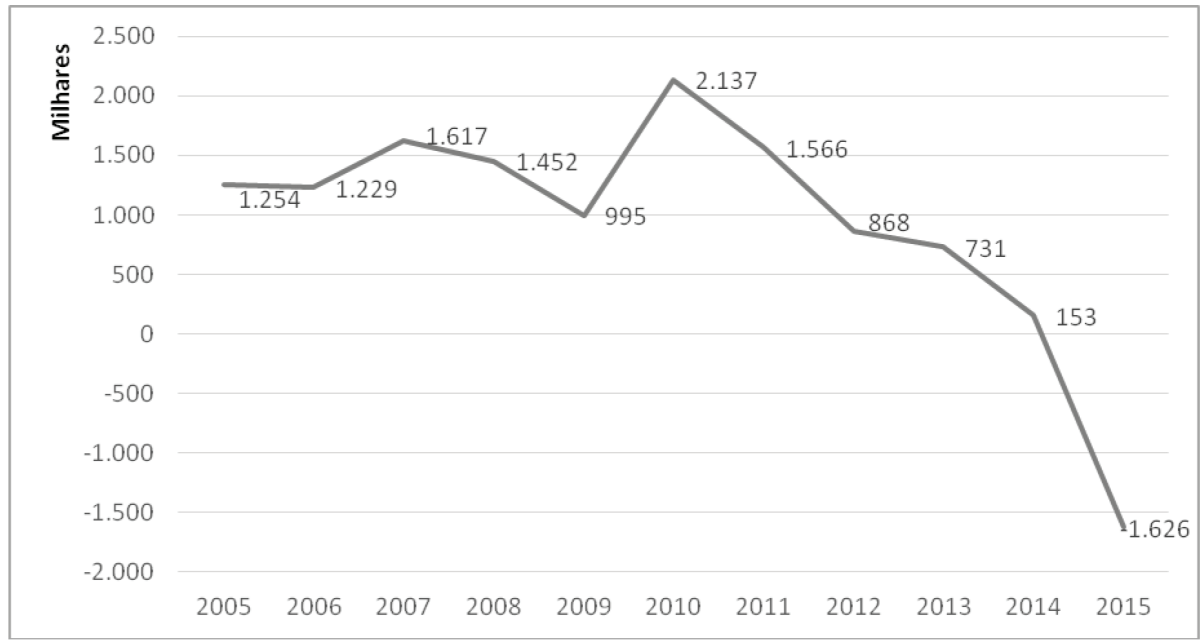

Fonte: CAGED/MTE, 2005-2015. Elaborado pelos autores.

Portanto, diante desse cenário de baixo crescimento econômico conjugado com o aumento do desemprego no país, como se comportou a dinâmica migratória nacional? Aumentou ou diminuiu a intensidade/volume da migração? As migraçóes de longa distância (inter-regional) permanecem se arrefecendo e as de média distância (intrarregional) e curta distância (intraestadual) crescem?

\section{PROCEDIMENTOS METODOLÓGICOS}

Este estudo tem como escopo geográfico de análise as cinco grandes regiōes brasileiras. O objetivo é captar a inter-relação entre a dinâmica migratória - por meio do fluxo migratório inter-regional (longa distância), intrarregional (média distância) e intraestadual (curta distância) durante os quinquênios de 2000/2005 e 2010/2015 - com as transformaçôes econômicas, notadamente no mercado trabalho, que aconteceram no Brasil e em suas cinco grandes regióes a partir do século XXI. Para tanto, os microdados da Pesquisa Nacional por Amostra de Domicílios (PNAD), dos anos de 2005 e 2015, disponibilizados pelo Instituto Brasileiro de Geografia e Estatística 
(IBGE), serão utilizados como fontes de informaçôes. O Cadastro Geral de Empregados e Desempregados (CAGED) e o IPEA-Data foram outras fontes de dados utilizadas.

As definiçôes adotadas no estudo são as seguintes:

Migrante inter-regional - indivíduo com cinco anos ou mais de idade que, na data de referência da pesquisa, residia em uma região, mas, em uma data fixa (exatamente cinco anos antes do levantamento), morava em outro estado de outra regiáo.

Migrante intrarregional - indivíduo com cinco anos ou mais de idade que, na data de referência da pesquisa, residia em uma região, e, em uma data fixa (exatamente cinco anos antes do levantamento), morava em outro estado da mesma regiáo.

Migrante Intraestadual - indivíduo com cinco anos ou mais de idade que, na data de referência da pesquisa, residia em um estado, e, em uma data fixa (exatamente cinco anos antes do levantamento), morava em outro município do mesmo estado.

Saldo migratório - representa a diferença entre o total de imigrantes e o de emigrantes.

A matriz migratória inter-regional que representa o fluxo entre as cinco grandes regióes do Brasil é apresentada sumariamente da seguinte forma:

$$
A=\left[\begin{array}{ccc}
a 11 & \cdots & a 1 j \\
\vdots & \ddots & \vdots \\
a j 1 & \cdots & a j j
\end{array}\right]
$$

$\mathrm{a}_{\mathrm{ij}}=$ saída do migrante da regiấo i para a regiấo $\mathrm{j}$

$$
\begin{aligned}
\sum_{j=1}^{5} a 1 j & =\text { total de pessoas que emigram (saída) da região } 1 \text { para } \\
& \text { as demais regiões do país. }
\end{aligned}
$$

$$
\sum_{j=1}^{5} \text { ail } \quad \begin{aligned}
& =\text { total de pessoas que imigram (entrada) das demais } \\
& \text { regiões do país para a região } 1 .
\end{aligned}
$$$$
\mathrm{a} 11=\mathrm{a} 22=\mathrm{a} 33=\ldots=\mathrm{ajj}=0
$$

Quanto à matriz migratória intrarregional e intraestadual, seu cálculo é feito com o mesmo procedimento de cálculo do fluxo inter-regional, sendo que o fluxo intrarregional ocorre entre os estados de uma mesma região e o intraestadual entre os municípios de um mesmo estado.

Outro recurso metodológico adotado foi cálculo do Índice de Eficácia Migratória (IEM), que permite aferir a capacidade de evasão, atração ou rotatividade migratória da região a partir do movimento total de entrada e de saída de pessoas, minimizando os efeitos do volume da imigração e da emigração (BAENINGER, 1999; IBGE, 2011a).

Em um cenário migratório distinto do observado no período 1950-1980, marcado pela predominância da migração rural-urbana e pelos fluxos de longa distância, a partir da década de 1980, a literatura aponta para mudanças na dinâmica migratória interna brasileira, com a diversificação das rotas migratórias, intensi- 
ficação dos movimentos migratórios de curta distância - dentro das regióes e dos próprios estados -, fluxos urbano-urbano, deslocamentos pendulares e sazonais, retorno e refluxos (PACHECO, PATARRA, 1997; MATOS, 2002). A partir dessas tendências, Baeninger (2012, p.12) reclassificou alguns conceitos usados em décadas passadas por considerá-los datados. Devem, portanto, ser substituídos, como é o caso dos seguintes:

a) áreas de evasão por áreas de perdas migratórias;

b) áreas de atração ou absorção por áreas de retenção migratória;

c) áreas de origem e destino por áreas/etapas constituintes dos processos de rotatividade migratória.

Assim, a referida autora propõe uma nova classificação ${ }^{2}$ para o cálculo do IEM, que ficou dividido em três áreas:

i) - 0,13 a -1,00: área de perda migratória;

ii) $-0,12$ a 0,12: área de rotatividade migratória;

iii) 0,13 a 1,00: área de retenção migratória.

O IEM varia entre -1 e +1 . Valores próximos a -1 representam áreas com perda migratória elevada; valores próximos a 1 dizem respeito a áreas que retêm a população; valores próximos a 0 (zero), áreas de rotatividade migratória (entradas e saídas de pessoas com volumes próximos). Tal indicador é calculado através do quociente entre a migração líquida (I-E) e a migração bruta (I+E), sendo obtido assim:

$$
I E M=\frac{(I-E)}{(I+E)}
$$

\section{OS FLUXOS DE MÉDIA (INTRARREGIONAL) E LONGA DISTÂNCIA (INTER-REGIONAL) NO BRASIL}

O volume da migração variou consideravelmente entre os quinquênios analisados: os dados da Tabela 1 indicam arrefecimento de grande monta nos fluxos de longa distância no período 2010/2015 em relação a 2000/2005, com volume aproximadamente $50 \%$ menor tanto para os fluxos interestaduais quanto se olharmos para os inter-regionais ou intrarregionais.

Tabela 1 - Volume da migração interestadual, inter-regional e intrarregional - Brasil $-2000 / 2005$ e $2010 / 2015$

\begin{tabular}{lccc}
\hline Fluxo migratório & $\mathbf{2 0 0 0 / 2 0 0 5}$ & $\mathbf{2 0 1 0 / 2 0 1 5}$ & Variaçáo (\%) \\
\hline Interestadual & 4.765 .406 & 2.401 .893 & $-49,60$ \\
Inter-regional & 3.031 .395 & 1.578 .926 & $-47,91$ \\
Intrarregional & 1.734 .011 & 822.967 & $-52,54$ \\
\hline
\end{tabular}

Fonte: Fundação IBGE. PNAD de 2005 e 2015. Tabulação e elaboração dos autores.

Segundo a Tabela 2, pode-se observar que o comportamento atingiu de maneira semelhante, em termos de volume, as grandes regióes brasileiras: Nordeste, Sudeste e
2 Até então, o índice era dividido em sete grupos: i) $-0,51$ a -1,00: área de forte evasão migratória; ii) $-0,30$ a -0,50: área de média evasão migratória; iii) -0,01 a -0,29: área de baixa evasão migratória; iv) 0,00 a 0,09: área de rotatividade migratória; v) 0,10 a 0,29: área de baixa absorção migratória; vi) 0,30 a 0,50: área de média absorção migratória; vii) 0,51 a 1,00: área de forte absorção migratória. 
Sul que apresentaram redução de pouco mais de $51 \%$ no volume, com destaque para o Norte, com queda da ordem de 58,4\%, seguido pelo Centro-Oeste $(54,96 \%)$.

Tabela 2 - Volume da migração intrarregional -- Brasil e Grandes Regiôes 2000/2005 e 2010/2015

\begin{tabular}{lccc}
\hline Regiáo & $\mathbf{2 0 0 0 / 2 0 0 5}$ & $\mathbf{2 0 1 0 / 2 0 1 5}$ & Variaçáo (\%) \\
\hline Norte & 198.119 & 82.424 & $-58,40$ \\
Nordeste & 398.389 & 194.346 & $-51,22$ \\
Sudeste & 643.522 & 313.915 & $-51,22$ \\
Sul & 297.209 & 143.665 & $-51,66$ \\
Centro-Oeste & 196.772 & 88.617 & $-54,96$ \\
\hline Brasil & $\mathbf{1 . 7 3 4 . 0 1 1}$ & $\mathbf{8 2 2 . 9 6 7}$ & $-52,54$ \\
\hline
\end{tabular}

Fonte: Fundação IBGE. PNAD de 2005 e 2015. Tabulaçáo e elaboração dos autores.

Além do arrefecimento dos fluxos, cabe destacar as mudanças em termos de saldo migratório observado. Nos dados da Tabela 3, dos mais de três milhôes de migrantes inter-regionais do período 2000/2005, o Sudeste predominava quanto ao saldo migratório negativo, de pouco mais de 315 mil pessoas, enquanto o Centro-Oeste, do outro lado, apresentou saldo positivo de mais de 222 mil pessoas.

Tabela 3 - Migração inter-regional - Brasil e Grandes Regiôes - 2000/2005

\begin{tabular}{|c|c|c|c|c|c|c|c|c|}
\hline \multirow{2}{*}{ Regióes } & \multirow{2}{*}{ NO } & \multirow{2}{*}{ NE } & \multirow{2}{*}{ SE } & \multirow{2}{*}{ SUL } & \multirow{2}{*}{$\mathrm{CO}$} & \multicolumn{2}{|c|}{ Emigrantes } & \multirow{2}{*}{$\begin{array}{c}\text { Saldo } \\
\text { Migratório }\end{array}$} \\
\hline & & & & & & Total & $(\%)$ & \\
\hline NO & - & 105.539 & 58.231 & 29.485 & 103.738 & 296.993 & 9,80 & 47.098 \\
\hline NE & 177.508 & - & 518.836 & 29.682 & 195.075 & 921.101 & 30,39 & -31.705 \\
\hline SE & 66.055 & 646.254 & - & 257.251 & 197.905 & 1.167 .465 & 38,51 & -315.721 \\
\hline SUL & 30.084 & 29.221 & 138.509 & - & 86.895 & 284.709 & 9,39 & 77.842 \\
\hline $\mathrm{CO}$ & 70.444 & 108.382 & 136.168 & 46.133 & - & 361.127 & 11,91 & 222.486 \\
\hline Imigrantes & 344.091 & 889.396 & 851.744 & 362.551 & 583.613 & 3.031 .395 & 100,00 & $\mathbf{0}$ \\
\hline Imigrantes (\%) & 11,35 & 29,34 & 28,10 & 11,96 & 19,25 & 100,00 & & \\
\hline
\end{tabular}

Fonte: Fundação IBGE. PNAD de 2005 e 2015. Tabulação e elaboração dos autores.

No período posterior, junto à queda do volume, houve aumento negativo de mais de quatro vezes no saldo migratório do Nordeste, enquanto o Sudeste reduziu consideravelmente o saldo negativo para pouco mais de 14 mil pessoas. Cabe destacar, nesse sentido, que tais alteraçóes se deram por motivos distintos: no caso do Sudeste, foi a emigraçáo que teve maior peso, visto que o volume caiu 54,6\% no segundo período em relação a 2000/2005, enquanto a imigração arrefeceu em $39,5 \%$. No Nordeste, por sua vez, enquanto a imigração caiu 53,5\%, a emigração apresentou redução menos intensa (39,0\%), fato que fez o saldo migratório negativo crescer consideravelmente. 
Quanto à relação das migraçóes com a recente crise econômica que se instaurou no país a partir de 2011, esses resultados ratificam a complexidade e interdisciplinaridade de se estudar a dinâmica migratória. Isso porque o pressuposto sobre as clássicas relaçôes entre migração-emprego, migração-industrialização e migração-crescimento econômico ou a abordagem teórica histórico-estrutural, em parte, explicam as causas e os motivos dos movimentos migratórios de média e, principalmente, de longa distância que, em geral, estão relacionados à busca de emprego e melhores condiçôes de vida (BAENINGER, 2005; BRITO, 2009). Contudo, o estudo em escala espacial menor, mais desagregada, como, por exemplo, em nível estadual, pode apontar particularidades e resultados diferentes do observado para a dinâmica migratória de longa e média distância.

A Tabela 4 também mostra que o Centro-Oeste, apesar de arrefecer o saldo migratório positivo, permanece como a região mais atrativa do país. O grande destaque, entretanto, foi a regiấo Sul, que aumentou o saldo migratório positivo entre os interregnos em estudo, caracterizado pelo declínio do volume migratório.

Tabela 4 - Migração inter-regional - Brasil e Grandes Regiōes - 2010/2015

\begin{tabular}{|c|c|c|c|c|c|c|c|c|}
\hline \multirow{2}{*}{ Regióes } & \multirow{2}{*}{ NO } & \multirow{2}{*}{$\mathrm{NE}$} & \multirow{2}{*}{ SE } & \multirow{2}{*}{ SUL } & \multirow{2}{*}{$\mathrm{CO}$} & \multicolumn{2}{|c|}{ Emigrantes } & \multirow{2}{*}{$\begin{array}{c}\text { Saldo } \\
\text { Migratório }\end{array}$} \\
\hline & & & & & & Total & $(\%)$ & \\
\hline NO & - & 48.041 & 37.171 & 17.136 & 61.958 & 164.306 & 10,41 & -62.728 \\
\hline $\mathrm{NE}$ & 48.617 & - & 357.132 & 38.176 & 117.855 & 561.780 & 35,58 & -148.331 \\
\hline SE & 12.028 & 282.982 & - & 131.916 & 102.690 & 529.616 & 33,54 & -14.557 \\
\hline SUL & 5.453 & 20.295 & 59.023 & - & 40.748 & 125.519 & 7,95 & 100.070 \\
\hline $\mathrm{CO}$ & 35.480 & 62.131 & 61.733 & 38.361 & - & 197.705 & 12,52 & 125.546 \\
\hline Imigrantes & 101.578 & 413.449 & 515.059 & 225.589 & 323.251 & 1.578 .926 & 100,00 & $\mathbf{0}$ \\
\hline Imigrantes(\%) & 6,43 & 26,19 & 32,62 & 14,29 & 20,47 & 100,00 & & \\
\hline
\end{tabular}

Fonte: Fundação IBGE. PNAD de 2005 e 2015. Tabulação e elaboração dos autores.

Ademais, os dados deste estudo revelam que tanto a migraçáo intrarregional (média distância) quanto a inter-regional (longa distância) arrefeceram em um cenário caracterizado por crise econômica, refutando alguns pressupostos teóricos que serviram para balizar os estudos nacionais.

A explicação para esse acontecimento/diminuição do volume migratório de médio e longo percurso deve estar relacionado com novos (programas de transferência de renda, preços dos imóveis nos grandes centros urbanos, programas habitacionais, violência, custo de vida nas grandes metrópoles, pressão nos serviços públicos, entre outros) e velhos elementos (fatores macrossociais, microssociais - trajetórias pessoais - e institucionais), que influenciaram o arrefecimento de tais fluxos vis-à-vis a intensificação do fluxo de curta distância (intraestadual), como será visto adiante.

O Índice de Eficácia Migratória (IEM) é outra ferramenta adotada neste estudo. Por meio dela, é possível traçar um breve panorama da dinâmica migratória inter-regional brasileira, a partir do movimento total de entrada e de saída de pessoas, independentemente do volume da imigração e da emigração. Esse indicador permitirá classificar as cinco grandes regióes do Brasil em área de perda, retenção ou rotatividade migratória.

Considerando o primeiro interregno em estudo (2000/2005), uma região tipificou como área de perda migratória (Sudeste), três como áreas de rotatividade 
(Norte, Nordeste e Sul) e o Centro-Oeste como área de retenção. Esse resultado é revelador de mudanças no cenário migratório nacional: algumas décadas atrás, não seria possível imaginar o Sudeste como uma região de perda de populaçáo enquanto o Norte, Sul e, principalmente, o Nordeste, com a sua histórica trajetória de perdas, como área de rotatividade.

Tabela 5 - Índice de Eficácia Migratória - Grandes Regiōes - 2000/2005 e 2010/2015

\begin{tabular}{lcc}
\hline \multicolumn{1}{c}{ Regióes } & \multicolumn{2}{c}{ Índice de Eficácia Migratória } \\
& $\mathbf{2 0 0 0 / 2 0 0 5}$ & $\mathbf{2 0 1 0 / 2 0 1 5}$ \\
\hline Norte & 0,07 & $-0,24$ \\
Nordeste & $-0,02$ & $-0,15$ \\
Sudeste & $-0,16$ & $-0,01$ \\
Sul & 0,12 & 0,29 \\
Centro Oeste & 0,24 & 0,24 \\
\hline
\end{tabular}

Fonte: Fundação IBGE. PNAD de 2005 e 2015. Tabulação e elaboração dos autores.

Com relação ao segundo interregno (2010/2015), constatam-se mudanças expressivas, dado que duas regióes passaram a tipificar como áreas de perda (Norte, Nordeste), sendo que no intervalo anterior figuravam como áreas de rotatividade. Por sua vez, o Sudeste passou a se enquadrar como regiáo de rotatividade, deixando de ser área de perda (2000/2005). Por outro lado, aumentou a quantidade de áreas de retenção (Sul e Centro Oeste), sendo que o Centro Oeste permanece na mesma condição do período anterior e o Sul deixou de ser área de rotatividade e tornou-se atrativo/retenção. Com isso, somente o Centro Oeste, nos dois momentos em análise, tipifica como área de retenção migratória, o que condiz com os resultados da variação da população ocupada e da PIA (Cf. Gráfico 1).

Portanto, fica evidente a complexidade de se estudar os fluxos migratórios nacionais, devido às suas inflexões, alternância de condição migratória, oscilaçóes no volume (imigrantes, emigrantes, saldos migratórios e IEM), direção (origem e destino) da população e inter-relação com a dinâmica econômica, notadamente com os efeitos da crise econômica, que parece "reviver" fluxos e dinâmicas que pareciam já ultrapassadas.

\section{OS FLUXOS DE CURTA DISTÂNCIA ( INTRAESTADUAL)}

Partimos da hipótese exposta anteriormente de que a redução da migração de média (intrarregional) e longa distância (inter-regional) seria resultado, concomitantemente, das novidades econômicas e sociais, bem como da queda na taxa de fecundidade materializadas no território e que, junto a essa redução, esperar-se-ia aumento da intensidade dos movimentos de curta distância, os fluxos intraestaduais.

Os dados da Tabela 6 apontam para redução do volume de migrantes intraestaduais no segundo quinquênio (2010/2015) em relação ao primeiro (2000/2005), de $20,1 \%$ para o país. Em relação às regiôes, o destaque fica com o Nordeste, com reduçấo de um quarto $(25,6 \%)$ enquanto o Centro-Oeste foi o que menos apresentou arrefecimento (12,1\%). 
Tabela 6 - Volume da migração intraestadual - Brasil e Grandes Regióes - 2000/2005 e 2010/2015

\begin{tabular}{lccc}
\hline Região & $\mathbf{2 0 0 0 / 2 0 0 5}$ & $\mathbf{2 0 1 0 / 2 0 1 5}$ & Variação (\%) \\
\hline Norte & 1.145 .014 & 882.590 & $-22,9$ \\
Nordeste & 3.133 .416 & 2.330 .997 & $-25,6$ \\
Sudeste & 4.367 .099 & 3.622 .686 & $-17,0$ \\
Sul & 2.170 .143 & 1.736 .939 & $-20,0$ \\
Centro-Oeste & 898.782 & 790.390 & $-12,1$ \\
\hline Brasil & $\mathbf{1 1 . 7 1 4 . 4 5 4}$ & $\mathbf{9 . 3 6 3 . 6 0 2}$ & $\mathbf{- 2 0 , 1}$ \\
\hline
\end{tabular}

Fonte: Fundação IBGE. PNAD de 2005 e 2015. Tabulação e elaboração dos autores.

A redução observada nos volumes é condizente com o contexto, diante da queda dos fluxos de média e longa distância pela metade (Cf. Tabelas 1 e 2). O que se destaca nesses dados é que, apesar da redução em termos de volume, o fluxo intraestadual (Tabela 6) permaneceu aproximadamente seis vezes maior quando comparado ao inter-regional (Tabela 4).

A Tabela 7 ratifica nossa hipótese ao mostrar um crescimento de $68,4 \%$ na intensidade dos movimentos intraestaduais em relação aos intrarregionais no Brasil, com destaque para a região Centro-Oeste, com crescimento de 95,3\% seguido pelo Norte $(85,3 \%)$.

Tabela 7 - Razão entre migrante intraestadual e migrante intrarregional - Brasil e Grandes Regiōes - 2000/2005 e 2010/2015

\begin{tabular}{lccc}
\hline Regiáo & $\mathbf{2 0 0 0 / 2 0 0 5}$ & $\mathbf{2 0 1 0 / 2 0 1 5}$ & Variaçáo (\%) \\
\hline Norte & 5,8 & 10,7 & 85,3 \\
Nordeste & 7,9 & 12,0 & 52,5 \\
Sudeste & 6,8 & 11,5 & 70,1 \\
Sul & 7,3 & 12,1 & 65,6 \\
Centro-Oeste & 4,6 & 8,9 & 95,3 \\
\hline Brasil & $\mathbf{6 , 8}$ & $\mathbf{1 1 , 4}$ & $\mathbf{6 8 , 4}$ \\
\hline
\end{tabular}

Fonte: Fundação IBGE. PNAD de 2005 e 2015. Tabulação e elaboração dos autores.

O crescimento da intensidade dos fluxos de curta distância sinaliza que, não obstante a redução generalizada dos volumes do segundo quinquênio (2010/2015) quando comparado com o primeiro (2000/2005), a migração não tornou-se menos importante enquanto estratégia de vida ou sobrevivência econômica, pelo contrário: os fluxos se alteraram como resultado dos distintos contextos político, econômico e demográfico (baixa natalidade), vividos em cada um desses períodos e em cada porção territorial. No segundo período, que marca uma das crises econômicas mais intensas experimentadas pelo país, a migração se modificou intensamente a partir de novos destinos e redução dos fluxos de longa e média distância e intensificação dos mais curtos: esses últimos caracterizam-se como movimentos menos custosos de ida e de volta, coerentes com um contexto de generalização do desemprego, subemprego e, consequentemente, de poucas oportunidades de inserção ocupacional.

Por outro lado, tal modificação ou intensificação do fluxo de curta distância foi

3 Essa razão foi calculada dividindo por região 0 volume de migrantes intraestaduais pelo volume de migrantes intrarregionais. 0 valor 6,8 , por exemplo, significa que no período 2000 2005 havia 6,8 migrantes intraestaduais para cada migrante intrarregional, ou seja, o volume do primeiro era 6,8 vezes maior do que no segundo. 
Ednelson Mariano Dota é Professor Adjunto do Departamento de Geografia e do Programa de Pós-graduação em Geografia da Universidade Federal do Espírito Santo (UFES). Geógrafo e Doutor em Demografia pela UNICAMP.

E-mail: ednelsondota@ gmail.com

ORCID: $\quad$ https://orcid. org/0000-0002-8726-0424

Silvana Nunes de Queiroz é Professora Adjunta do Departamento de Economia da Universidade Regional do Cariri (URCA) e do Programa de Pós-Graduação em Demografia da Universidade Federal do Rio Grande do Norte (UFRN). Economista e Doutora em Demografia pela UNICAMP.

E-mail: silvanaqueirozce@ yahoo.com.br

ORCID: https://orcid.org/ 0000-0001-7295-3212

Este trabalho é resultado de projeto de pesquisa financiado pela FAPES/CNPq, processo número 80605869 , TO 129/17. As opiniões, hipóteses e conclusões são de responsabilidade dos autores e não necessariamente refletem a visão da FAPES e/ou do CNPq.

Artigo recebido em 28 de abril 2018 e aprovado para publicação em 08 de março de 2019.

Artigo licenciado sob Licença Creative Commons (CC-BY). possível pela dinamização interna de cada uma das regióes, dadas tanto por políticas públicas de diversas ordens, com destaque para os investimentos nas áreas de saúde, infraestrutura e, notadamente educação implementados pelo Governo Federal e pelos governos estaduais (JUSTINO, 2018).

Ademais, novos fenômenos que fazem parte das estratégias de reprodução social de famílias e indivíduos, como é o caso da mobilidade pendular (fluxo diário de casa para trabalho ou estudo), estão presentes cada vez mais nos municípios do interior do Brasil e não somente em regiōes metropolitanas, mostrando a força de novas modalidades migratórias ou fluxos migratórios, em espaços cada vez menores, onde é preciso percorrer menor distância para realizar suas atividades (SILVA, 2019).

\section{CONSIDERAÇÕES FINAIS}

Os dados comparativos de migração inter-regional, intrarregional e intraestadual do Brasil da primeira metade da década de 2000 e primeira metade da década de 2010 permitem afirmar que a crise econômica vivenciada a partir de 2011 afetou drasticamente a migração. Assim, como observado na década de 1980 (MARTINE; NEIVA; MACEDO, 1984; PACHECO; PATARRA, 1997; CUNHA; BAENINGER, 2007), houve redução dos volumes em todas regióes, com mudança no cenário de atração/ circulação/expulsão em muitas delas.

No caso específico do Sudeste e do Nordeste, protagonistas dos grandes fluxos migratórios no Brasil, a inversão da dinâmica aponta para o renascimento de tendências de décadas anteriores como resultado da crise econômica vivenciada pelo país, a partir da histórica complementaridade migratória entre essas regióes. Neste contexto, os resultados mostram-se consistentes com os papéis historicamente desempenhados por essas duas grandes regióes na dinâmica migratória nacional. Contudo, novos destinos são redefinidos, o Sudeste deixa de ser um espaço de atração no fluxo migratório inter-regional (longa distância).

Outro dado revelado pelo estudo aponta para a importância da migraçáo de curta distância (intraestadual). Apesar do seu arrefecimento, em termos de volume, tendência também apresentada pelo fluxo inter-regional e intrarregional, fica evidente a proeminência dessa modalidade migratória em nível nacional. As transformaçóes territoriais, sociais, econômicas e demográficas em consequência da queda na taxa de fecundidade ocorrida nestes últimos 30 anos estão materializadas nos inúmeros estudos que acompanham as mudanças na dinâmica migratória no Brasil, que não foram poucas.

Os resultados deste estudo, entretanto, reiteram alguns pontos e apontam para algumas novidades, sobretudo (1) o papel do contexto econômico como importante condicionante para os fluxos de média e longa distância, tendo em vista o relevante impacto na migração como resultado da crise; (2) a continuidade das históricas relaçôes entre as regiôes, a partir do retorno a antigos padrôes de trocas, principalmente entre o Sudeste e o Nordeste; (3) a novidade de o Centro-Oeste ser a regiáo mais atrativa do país; (4) a importância crescente da migração de curta distância vis-à-vis a migração de média e longa distância.

Por fim, as desigualdades regionais continuam a condicionar os fenômenos 
sociais e migratórios, apesar das transformaçóes vivenciadas pelo país e por suas regiōes no período considerado. A dimensão econômica, associada a essas desigualdades, parece permanecer em destaque tanto quanto antes, o que impóe a necessidade de aprofundar a sua análise.

Sendo assim, os achados neste estudo revelam a complexidade de se estudar as migraçôes internas em tempos de crise, dado que estamos diante de "velhos' fluxos, marcado por corrente e contracorrente migratória e, ao mesmo tempo, diante de novas tendências, novos destinos e uma escala de deslocamento cada vez menor.

\section{REFERÊNCIAS BIBLIOGRÁFICAS}

BAENINGER, R. Migraçóes internas no Brasil no século 21: entre o local e o global. In: Anais do XVIII Encontro Nacional de Estudos Populacionais (ABEP), 2012. Rotatividade migratória: um novo olhar para as migraçóes no século XXI. Anais do XVI Encontro Nacional de Estudos Populacionais (ABEP), 2008. Sáo Paulo e suas Migraçóes no final do Século 20. Sáo Paulo em Perspectiva (Impresso), São Paulo, SP., v. 19, n.3, 2005.

BRITO, F. A transição para um novo padrão migratório no Brasil. Textos para discussão. Belo Horizonte: UFMG/Cedeplar, 2015. As migraçóes internas no Brasil: um ensaio sobre os desafios recentes. In: Anais do VI Encontro Nacional sobre Migraçóes. Campinas: ABEP, 2009.

BRITO, F. CARVALHO, J.A.M; TURRA, C.M.; QUEIRÓZ, B.L. A transição demográfica e as políticas sociais no Brasil. Pág. 19-62 in BRITO, F. e BAENINGER, R. (coords.) Populaçóes e Políticas sociais no Brasil: os desafios da transiçáo demográfica e das migraçóes internacionais. Brasília, CGEE, 2008.

CAMPOS, G. C. de S. O emprego formal no Brasil dos anos 2000: um estudo da Relaçáo Anual de Informaçóes Sociais (2003-2013). Tese de doutoramento (economia). Campinas: Unicamp/IE, 2016.

CASTIGLIONI, A. H. Migração: abordagens teóricas. In: ARAGÓN, L. E. Migração Internacional na Pan-Amazônia. Belém: NAEA/UFPA, v. 1, p. 39-57, 2009.

CUNHA, J. M. P. da; BAENINGER, R. Las migraciones internas em el Brasil Comtemporáneo. Notas de Población, CEPAL/CELADE, Año XXXII, n. 82, 2007.

CUNHA, J. M. P. da. “Apresentação”. In: CUNHA, J. M. P. da (org.) Mobilidade espacial da populaçáo: desafios teóricos e metodológicos para o seu estudo. Campinas: NEPO/UNICAMP, 2011.

DEDECCA, C. S.; ROSANDISKI, E. N. Recuperaçáo econômica e a geraçáo de empregos formais. Parcerias Estratégicas. Brasília: Centro de Gestão e Estudos Estratégicos, Ministério da Ciência e Tecnologia. n. 22, 2006.

DIEESE. A Situaçáo do trabalho no Brasil na primeira década dos anos 2000. São Paulo: Departamento Intersindical de Estatística e Estudos Socioeconômicos, 2012.

GAUDEMAR, J. P. Mobilidade do trabalho e acumulaçáo do capital. Lisboa: Estampa, 1977.

MATOS, R. E. S. A contribuição dos imigrantes em áreas de desconcentração demográfica do Brasil contemporâneo. Revista Brasileira de Estudos de Populaçáo, Campinas, v.19, n.1, p.49-72, 2002.

JUSTINO, T. S. O efeito da expansão da educaçáo superior na pendularidade no Nordeste Brasileiro em 2000 e 2010. Dissertação (Mestrado em Demografia-UFRN), 2018.

MARTINE, G; NEIVA, I.C; MACEDO, M. Migração, crise e outras agurras. In: Anais do 
IV Encontro Nacional de Estudos Populacionais (ABEP), 1984.

NUNES, E. S.; SILVA, J. G.; QUEIROZ, S. N. de. Migração inter-regional no Brasil: o que há de novo? In: Anais do XVII Encontro Nacional da Associação Nacional de Pós-Graduaçáo e Pesquisa em Planejamento Urbano e Regional (ENANPUR), 2017.

PACHECO, C. A.; PATARRA, N. L. "Movimentos migratórios anos 80: novos padrôes?”. In: Anais do Encontro Nacional sobre Migração, v. 1, p. 445-462, 1997.

PAULA, L. F. R.; PIRES, M. C. C. Crise e perspectivas para a economia brasileira. Estudos Avançados (USP. Impresso), v. 31, p. 125-144, 2017.

SILVA, J. G. da. Características da mobilidade inter e intramunicipal por motivo de trabalho: Evidências para o Brasil. Dissertação (Mestrado em Demografia-UFRN), 2019.

SINGER, P. Economia política e urbanização. 3ed. CEBRAP, Brasiliense, 1976.

QUADROS, W. J. Em 2009 a heterodoxia afastou a crise social. Texto para Discussão. IE/ UNICAMP, n. 189, março 2011.

ZELINSKY, W. The impasse in migration: a sketch map for potencial scapes. In: MORRISON, P. (Ed.). Population movements: their forms and functions in urbanization and development. Liège: Ordina Ed., 1980. 